Disclosure of Interests: Brian LaMoreaux Shareholder of: Horizon Therapeutics, Employee of: Horizon Therapeutics, Megan Francis-Sedlak Shareholder of: Horizon Therapeutics, Employee of: Horizon Therapeutics, Robert Holt Shareholder of: Horizon Therapeutics, Employee of: Horizon Therapeutics DOI: 10.1136/annrheumdis-2020-eular.2058

\section{OP0171 \\ MENDELIAN RANDOMIZATION SHOWS NO CAUSAL ASSOCIATION BETWEEN SERUM URATE OR GOUT AND TYPE-2 DIABETES}

N. Mccormick ${ }^{1,2}$, J. Choi ${ }^{3}$, S. Marozoff ${ }^{2}$, H. Choi ${ }^{1,2} .{ }^{1}$ Massachusetts General Hospital/Harvard Medical School, Boston, United States of America; ${ }^{2}$ Arthritis Research Canada, Richmond, Canada; ${ }^{3}$ Massachusetts General Hospital, Boston, United States of America

Background: Positive associations between gout ${ }^{1,2}$ or serum urate $(\mathrm{SU})^{3}$ and risk of type-2 diabetes (T2D) have been reported in population-based observational studies, but may be due to residual confounding. As such, causal roles of SU and gout on development of T2D are unclear.

Objectives: Use two-sample mendelian randomization to estimate the causal effects of SU and gout on T2D and glycemic traits.

Methods: Aggregate data from three large genome-wide association studies were used to identify genetic variants (SNPs) associated with the exposures and outcomes. Exposure SNPs were sourced from Global Urate Genetics Consortium (> 140,000 individuals); outcome SNPs sourced from DIAbetes Genetics Replication And Meta-analysis consortium (DIAGRAM; > 34,000 T2D cases and $>114,000$ controls) and Meta-Analyses of Glucose and Insulin-related traits Consortium (MAGIC; > 46,000 non-diabetics).

We analysed SNPs associated with SU levels $(n=28)$ and gout $(n=6)$ for associations with T2D and three glycemic traits (insulin resistance, fasting insulin levels, and $\mathrm{HbA1c}$ ) using inverse variance weighted meta-analysis methods. We also specifically examined two SNPS mapping to the SLC2A9 gene, which encodes the GLUT9 transporter (for glucose and urate), estimating Wald ratios for these individual SNPs. Analyses were performed with TwoSampleMR package in R and mRnd power calculator.

Results: Estimated effects of genetically-determined gout on each of the four outcomes (T2D, insulin resistance, fasting insulin levels, and $\mathrm{HbA} 1 \mathrm{c}$ ) were small and non-significant $(p \geq 0.18)$, as were the effects of changes in genetically-determined SU levels (Table)

Although the two SNPS in the SLC2A9 gene were strongly associated with SU ( $r$ 12498742: $R^{2}=2.7 \%$, beta $=0.37$ per $\mathrm{mg} / \mathrm{dL}, \mathrm{p}<10^{-700}$ ) and gout ( $\mathrm{rs} 4475146$ : odds ratio $=0.63, p=4.1 \times 10^{-26}$ ), neither was associated with T2D nor any of the glycemic traits (Table).

Applying $\mathrm{R}^{2}$ values $\geq 1.9 \%$, we had $\geq 90 \%$ power to detect the increased odds of $\mathrm{T} 2 \mathrm{D}\left(\mathrm{OR} \geq 1.15^{1,3}\right)$ from observational studies.

\begin{tabular}{|c|c|c|c|c|c|}
\hline \multicolumn{6}{|c|}{ All Risk SNPs (meta-analysis) } \\
\hline \multirow[t]{2}{*}{ OUTCOME } & \multirow[t]{2}{*}{ n SNPs } & \multicolumn{2}{|c|}{$\begin{array}{c}\text { Gout } \\
\text { (vs. non-gout) }\end{array}$} & \multicolumn{2}{|c|}{$\begin{array}{l}\text { Serum urate (per } 1 \mathrm{mg} / \\
\mathrm{dL} \text { increase) }\end{array}$} \\
\hline & & $\begin{array}{l}\text { Effect size } \\
(95 \% \mathrm{Cl})\end{array}$ & $\mathrm{p}$ & $\begin{array}{l}\text { Effect size } \\
(95 \% \mathrm{Cl})\end{array}$ & $\mathrm{p}$ \\
\hline $\mathrm{HbA1c}(\%)$ & 45 & $\begin{array}{l}0.0046(-0.0087 \\
\quad \text { to } 0.0179)\end{array}$ & 0.50 & $\begin{array}{c}-0.0046(-0.0275 \\
\text { to } 0.0183)\end{array}$ & 0.70 \\
\hline $\begin{array}{l}\text { Insulin resistance } \\
\text { (HOMA-IR: log units) }\end{array}$ & 45 & $\begin{array}{l}0.0108(-0.0049 \\
\text { to } 0.0265)\end{array}$ & 0.18 & $\begin{array}{l}0.0016(-0.0240 \\
\text { to } 0.0272)\end{array}$ & 0.90 \\
\hline $\begin{array}{l}\text { Fasting insulin levels } \\
\quad(\log \mathrm{pmol} / \mathrm{L})\end{array}$ & 18 & $\begin{array}{l}0.0046(-0.0037 \\
\quad \text { to } 0.0129)\end{array}$ & 0.28 & $\begin{array}{l}-0.0221(-0.1035 \\
\text { to } 0.0593)\end{array}$ & 0.59 \\
\hline $\begin{array}{l}\text { Type } 2 \text { Diabetes: odds } \\
\text { ratio }\end{array}$ & 43 & $\begin{array}{c}0.98(0.90 \text { to } \\
1.07)\end{array}$ & 0.72 & 1.01 (0.88 to 1.16$)$ & 0.84 \\
\hline
\end{tabular}

SNPs in SLC29A Gene (single-SNP analysis)

\begin{tabular}{|c|c|c|c|c|}
\hline \multirow[t]{2}{*}{ OUTCOME } & \multicolumn{2}{|c|}{$\begin{array}{c}\text { rs4475146 } \\
\text { Gout } \\
\text { (vs. non-gout) }\end{array}$} & \multicolumn{2}{|l|}{$\begin{array}{c}\text { rs12498742 } \\
\text { Serum urate (per } \\
1 \mathrm{mg} / \mathrm{dL} \text { increase) }\end{array}$} \\
\hline & $\begin{array}{c}\text { Effect size } \\
(95 \% \mathrm{Cl})\end{array}$ & $\mathbf{p}$ & $\begin{array}{l}\text { Effect size }(95 \% \\
\text { Cl) }\end{array}$ & $\mathbf{p}$ \\
\hline $\mathrm{HbA1c}(\%)$ & $\begin{array}{l}0.0032(-0.0139 \\
\quad \text { to } 0.0203)\end{array}$ & 0.71 & $\begin{array}{l}0.0005(-0.0205 \\
\text { to } 0.0216)\end{array}$ & 0.96 \\
\hline $\begin{array}{l}\text { Insulin resistance (HOMA-IR: log } \\
\text { units) }\end{array}$ & $\begin{array}{l}0.0128(-0.0073 \\
\quad \text { to } 0.0328)\end{array}$ & 0.21 & $\begin{array}{l}0.0126(-0.0121 \\
\text { to } 0.0373)\end{array}$ & 0.32 \\
\hline Fasting insulin levels (log pmol/L) & $\begin{array}{c}0.0038(-0.0070 \\
\text { to } 0.0147)\end{array}$ & 0.49 & $\begin{array}{c}0.0048(-0.0088 \\
\text { to } 0.0185)\end{array}$ & 0.49 \\
\hline Type 2 Diabetes: odds ratio & 0.98 (0.87 to 1.10$)$ & 0.70 & 0.98 (0.85 to 1.13$)$ & 0.75 \\
\hline
\end{tabular}

HOMA-IR=homeostasis model assessment of insulin resistance
Conclusion: Evidence from this instrumental variable analysis suggests gout and SU are signals for future T2D, but neither SU or gout itself are causally associated with the development of this condition. As such, interventions targeting SU levels alone are unlikely to lower the risk of T2D.

References:

[1] Rho YH, Lu N, Peloquin CE, et al. Independent impact of gout on the risk of diabetes mellitus among women and men: a population-based, BMImatched cohort study. Ann Rheum Dis. 2016;75(1):91-95.

[2] Choi HK, De Vera MA, Krishnan E. Gout and the risk of type 2 diabetes among men with a high cardiovascular risk profile. Rheumatology. 2008;47(10):1567-1570.

[3] Bhole V, Choi JWJ, Woo Kim S, De Vera M, Choi H. Serum Uric Acid Levels and the Risk of Type 2 Diabetes: A Prospective Study. Am J Med. 2010;123(10):957-961.

Disclosure of Interests: Natalie McCormick: None declared, Jeewoong Choi: None declared, Shelby Marozoff: None declared, Hyon Choi Grant/research support from: $\mathrm{HC}$ reports research support from Ironwood and Horizon, Consultant of: HC reports consulting fees from Ironwood, Selecta, Horizon, Takeda, Kowa, and Vaxart.

DOI: 10.1136/annrheumdis-2020-eular.3238

\section{OP0172 1 EFFECT OF WEIGHT LOSS AND LIRAGLUTIDE ON SERUM URATE LEVELS AMONG OBESE KNEE OSTEOARTHRITIS PATIENTS: SECONDARY ANALYSIS OF A RANDOMISED CONTROLLED TRIAL}

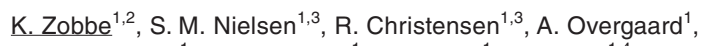

H. Gudbergsen ${ }^{1}$, M. Henriksen ${ }^{1}$, H. Bliddal ${ }^{1}$, L. Dreyer ${ }^{1,4}$, L. Stamp ${ }^{5}$, F. Krag $\mathrm{Knop}^{6,7}$, L. E. Kristensen ${ }^{1} .{ }^{1}$ The Parker Institute, Bispebjerg-Frederiksberg Hospital, University of Copenhagen, Frederiksberg, Denmark; ${ }^{2}$ Center for Rheumatology and Spine Diseases, Rigshospitalet Gentofte, Hellerup, Denmark; ${ }^{3}$ Department of Rheumatology, Odense University Hospital, Odense, Denmark; ${ }^{4}$ Department of Rheumatology, Aalborg University Hospital, Aalborg, Denmark; ${ }^{5}$ Department of Medicine, University of Otago, Christchurch, New Zealand; ${ }^{6}$ Center for Clinical Metabolic Research, Gentofte Hospital, University of Copenhagen, Hellerup, Denmark; ${ }^{7}$ Department of Clinical Medicine, Faculty of Health and Medical Sciences, University of Copenhagen, Copenhagen, Denmark

Background: There is a strong association between gout and obesity. Lowering urate is the cornerstone of gout management [1] and urate levels correlate strongly with central obesity. Previous studies suggest that weight loss has a positive effect on serum urate, however, the studies are sparse and small [2].

Objectives: To assess the impact of an initial low-calorie diet-induced weight loss and subsequent randomisation to the body weight-lowering drug liraglutide (a glucagon-like peptide 1 receptor agonist) or placebo on serum urate levels.

Methods: In the LOSE-IT trial (NCT02905864), a randomised, double-blinded, placebo-controlled, parallel group, single-centre trial [3], 156 obese individuals with knee osteoarthritis, but without gout, were offered an initial 8-week intensive diet intervention (week -8 to 0) on Cambridge Weight Plan (800-1000 kcal/ day) followed by a weight loss maintenance period in which participants were randomised to either liraglutide $3 \mathrm{mg} /$ day or placebo for 52 weeks. We conducted a secondary analysis of blood samples collected at week $-8,0$ and 52 . The primary outcome measure was change in serum urate. We used paired t-test for the change from week -8 to 0 , and for change from week 0 to 52 we used an ANCOVA model adjusted for stratification factors (sex, age category and obesity class), and the level of the outcome at baseline. Data were analysed as observed (i.e. no imputation of missing data).

Results: 156 individuals were randomised and 155 had blood samples taken at baseline. In the initial intensive diet intervention period (week - 8 to 0 ) they lost a mean of $12.5 \mathrm{~kg}(95 \% \mathrm{Cl}-13.1$ to $-11.9, \mathrm{n} \mathrm{156)}$. In the following 52 weeks, the liraglutide group lost an additional $4.1 \mathrm{~kg}$ (SE 1.2, n 71) whereas the control group was almost unchanged with a weight loss of $0.2 \mathrm{~kg}$ (SE 1.2, $\mathrm{n}$ 66). Looking at the main outcome of serum urate levels change, the initia intensive diet resulted in a mean decrease of $0.21 \mathrm{mg} / \mathrm{dL}(95 \% \mathrm{Cl} 0.35$ to $0.07, n$ 155) for the entire cohort. In the following year (week 0 to 52 ) the liraglutide group exhibited a further mean decrease in serum urate of $0.48 \mathrm{mg} /$ $\mathrm{dL}$ (SE 0.11, n 69), whereas the placebo group exhibited a slight decrease in mean serum urate of $0.07 \mathrm{mg} / \mathrm{dL}$ (SE $0.12, \mathrm{n} \mathrm{65}$ ) resulting in a significant between-group difference of $-0.40 \mathrm{mg} / \mathrm{dL}(95 \% \mathrm{Cl}-0.69$ to $-0.12, \mathrm{n} 134)-$ see Figure 1. Four participants in each group experienced serious adverse events; no deaths were observed.

Conclusion: This secondary analysis of the LOSE-IT trial suggests that liraglutide provides a potential novel serum urate lowering drug mechanism in obese patient populations, with potential implication for gout treatment. 
References:

[1] Richette P et al. 2016. Ann Rheum Dis 2017;76:29-42.

[2] Nielsen SM et al. Ann Rheum Dis 2017 76(11):1870-1882.

[3] Gudbergsen $\mathrm{H}$ et al. BMJ 2019. 71-2.

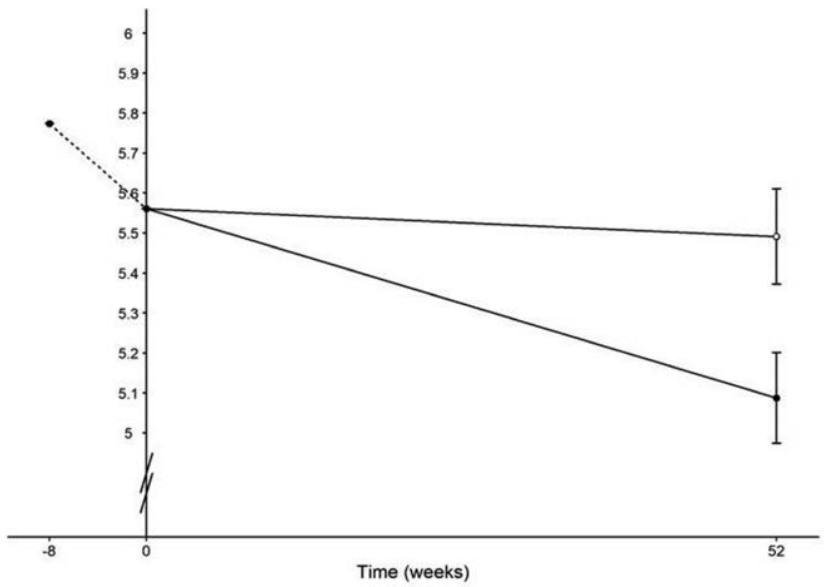

Figure 1: Serum urate at different timepoints: Estimates are unadjusted means at week -8 and 0 (dotted line; $\mathrm{n}=155$ ) and least square means estimates from an ANCOVA model (adjusted for stratification factors, i.e. sex, age category, obesity class as well as the level of the outcome at baseline) for data at 52 weeks (solid lines; $n=134)$. Solid points at week 52 indicate the liraglutide group $(n=69)$ and open points indicate the placebo group $(n=65)$. The error bars indicate SE.

Disclosure of Interests: Kristian Zobbe: None declared, Sabrina Mai Nielsen: None declared, Robin Christensen: None declared, Anders Overgaard: None declared, henrik gudbergsen Speakers bureau: Pfizer 2016, Marius Henriksen: None declared, Henning Bliddal Grant/research support from: received research grant fra NOVO Nordic, Consultant of: consultant fee fra NOVO Nordic, Lene Dreyer: None declared, Lisa Stamp: None declared, Filip Krag Knop Shareholder of: Minority shareholder in Antag Therapeutics Aps, Grant/research support from: AstraZeneca, Gubra, Novo Nordisk, Sanofi and Zealand Pharma, Consultant of: Amgen, AstraZeneca, Boehringer Ingelheim, Carmot Therapeutics, Eli Lilly, MSD/Merck, Mundipharma, Novo Nordisk, Sanofi and Zealand Pharma., Speakers bureau: AstraZeneca, Bayer, Boehringer Ingelheim, Eli Lilly, Medlmmune, MSD/Merck, Mundipharma, Norgine, Novo Nordisk, Sanofi and Zealand Pharma., Lars Erik Kristensen Consultant of: UCB Pharma (Advisory Board), Sannofi (Advisory Board), Abbvie (Advisory Board), Biogen (Advisory Board), Speakers bureau: AbbVie, Amgen, Biogen, Bristol-Myers Squibb, Celgene, Eli Lilly, Gilead, Forward Pharma, Janssen Pharmaceuticals, MSD, Novartis, Pfizer, and UCB Pharma

DOI: 10.1136/annrheumdis-2020-eular.3088

\section{OP0173 \\ IMMUNOMODULATION CO-THERAPY WITH PEGLOTICASE: DATABASE TRENDS 2014-2019}

B. Lamoreaux ${ }^{1}$, M. Francis-Sedlak ${ }^{1}$, K. Svensson ${ }^{1}$, R. Holt ${ }^{1} .{ }^{1}$ Horizon Therapeutics, Lake Forest, United States of America

Background: Pegloticase is a PEGylated biologic therapy for patients with uncontrolled gout who have not improved on or could not tolerate conventional urate-lowering therapies. ${ }^{1}$ All biologics have the ability to engender anti-drug antibodies (ADAs) and it is known that some patients given pegloticase develop ADAs that cause them to stop treatment prior to recieving a complete course of therapy. ${ }^{2-3}$ In other rheumatic autoimmune diseases, DMARDs such as methotrexate or azathioprine are used as standard of care to prevent the development of ADAs to biologics. These DMARDs often allow patients to remain on biologic therapies longer and recieve the full therapeutic benefits while minimizing adverse events. ${ }^{4}$ While pegloticase has been used traditionally as monotherapy, recent case series have demonstrated the therapeutic benefit of immunomodulator co-administration, allowing more patients to receive a full course of pegloticase therapy. ${ }^{5-6}$ Little has been published on how widespread this practice is and whether it has changed over time.

Objectives: To examine medical claims database from 2014-2019 for trends in immunomodulating therapies being co-prescribed with pegloticase.

Methods: An IQVIA claims database (November 2014 to October 2019) representing 1.3 billion claims, covering 30 million patients diagnosed with gout or CKD, was utilized to search for patients who had received pegloticase. Patients who had recieved pegloticase were classified as having been on an immunomodulating co-therapy if they were prescribed methotrexate or azathioprine within 60 days before or after initiation of their first pegloticase infusion.
Results: We found relatively steady low rates of immunomodulation co-therapy with pegloticase from 2014 through 2018 ranging from 1\% in 2016 to $4 \%$ in 2018 (Figure 1). In 2019 however, the proportion of pegloticase patients that were co-treated with methotrexate or azathioprine therapy increased to $15 \%$. Most patients were started on immunomodulating therapy 20 days before to 10 days after initiation of pegloticase. Methotrexate was the more frequently used immunomodulaton co-therapy as compared to azathioprine.

Figure 1: Proportion of pegloticase patients receiving immunomodulation therapy by year

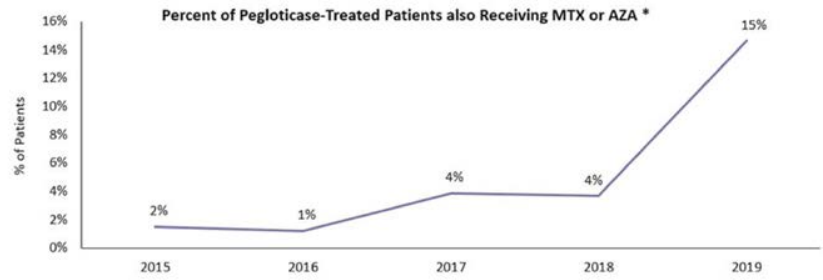

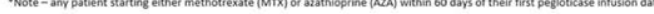

Conclusion: We found evidence of a relatively dramatic increasing initiation of immunomodulation therapy with pegloticase beginning soon after a November 2018 presentation of a case series which demonstrated improved response rates of pegloticase when co-administered with methotrexate. These data indicate that clinicians began to more frequently employ a strategy of DMARD co-treatment with pegloticase in 2019 to improve response rates to this important gout medicine.

References:

[1] Sundy JS, et al. JAMA 2011;306:711-20.

[2] Abeles AM. Arthritis Research \& Therapy 2014, 16:112

[3] Strand V, et al. BioDrugs 2017; 31:299-316.

[4] Krieckaert CL, et al. Arthritis Res Ther 2010;12:217.

[5] Botson J and Peterson J. Ann Rheum Dis. 2019; 78: A1289

[6] Bessen SY, et al. Semin Arthritis Rheum. 2019;49:56-61.

Disclosure of Interests: Brian LaMoreaux Shareholder of: Horizon Therapeutics, Employee of: Horizon Therapeutics, Megan Francis-Sedlak Shareholder of: Horizon Therapeutics, Employee of: Horizon Therapeutics, Karl Svensson Shareholder of: Horizon Therapeutics, Employee of: Horizon Therapeutics, Robert Holt Shareholder of: Horizon Therapeutics, Employee of: Horizon Therapeutics

DOI: 10.1136/annrheumdis-2020-eular.3893

\section{\begin{tabular}{|l|l}
\hline OP0174 POLYDATIN PREVENTS CALCIUM PYROPHOSPHATE \\
\hline
\end{tabular} CRYSTAL-INDUCED ARTHRITIS IN MICE}

F. Oliviero ${ }^{1}$, F. Galuppini ${ }^{1}$, A. Scanu ${ }^{1}$, P. Galozzi ${ }^{1}$, V. Lazzarin ${ }^{1}$, P. Sfriso ${ }^{1}$, G. Ravagnan ${ }^{2}$, R. Ramonda ${ }^{1}$, P. Spinella ${ }^{1}$, L. Punzi ${ }^{3}$, G. Pennelli ${ }^{1}$, R. Luisetto ${ }^{1} .{ }^{1}$ University of Padova, Padova, Italy; ${ }^{2}$ Institute of Translational Pharmacology CNR, Rome, Italy; ${ }^{3}$ Ospedale SS Giovanni e Paolo, Venezia, Italy

Background: Acute calcium pyrophosphate (CPP) crystal-induced inflammation is characterized by the massive release of cytokines and pro-inflammatory mediators and, from a clinical point of view, pain and limited joint function. Contrary to the precipitation of urate crystals that can be prevented through the use of hypouricemic drugs, there is no pharmacological therapy that can prevent the formation of pyrophosphate crystals.

Polydatin (PD), a natural precursor of resveratrol, is a stilbenoid mainly contained in grape juice and bark of Polygonum Cuspidate. Its antioxidant, anti-inflammatory and immunomodulating properties have been demonstrated in several experimental models. We have recently shown that this compound is able to prevent the inflammatory response to pathogenic crystals in vitro (1)

Objectives: The aim of this study was to assess the anti-inflammatory preventing effect of polydatin in the mouse model of acute crystal-induced arthritis. Methods: A suspension of sterile CPP crystals $(0.3 \mathrm{mg} / 20 \mu \mathrm{L}$ PBS) have been injected intra-articularly (i.a.) into one ankle joint of Balb/c mice under isoflurane anesthesia. Animals were randomized in 5 groups: 1- CPP injection, 2- CPP + PD, 3- CPP + colchicine (control drug), 4- CPP + vehicle (control. N 1), 5- PBS injection (control N. 2). Polydatin and colchicine were administered by gavage (respectively $40 \mathrm{mg} / \mathrm{kg}$ and $1 \mathrm{mg} / \mathrm{kg}$ in $200 \mu \mathrm{L} \mathrm{PBS} / \mathrm{EtOH} /$ glucose) at 24, 15 and $1 \mathrm{~h}$ before and 1, 6 and $24 \mathrm{~h}$ after (prophylactic model) or 1, 6 and $24 \mathrm{~h}$ after (ther apeutic model) i.a. injection of CPP crystals.

Ankle swelling was measured at different time points using a precision caliper. After $48 \mathrm{~h}$ (peak of the acute phase) mice were euthanized and blood and ankle 